\title{
Spectroscopic Studies and Molecular Modeling for Understanding the Interactions Between Cholesterol and Cyclodextrins
}

\author{
Delphine Castagne ${ }^{\mathrm{a}}$, Georges Dive ${ }^{\mathrm{b}}$, Brigitte Evrard $^{\mathrm{a}}$, Michel Frédérich $^{\mathrm{c}}$, Géraldine Piel $^{\mathrm{a}}$ \\ a Laboratory of Pharmaceutical Technology, CIRM, Department of Pharmacy, University of Liège, 1 av. de l'Hôpital, \\ B-4000 Liège, Belgium, E-mail address: dcastagne@ulg.ac.be \\ ${ }^{\mathrm{b}}$ Center for Protein Engineering, Chemical Department, University of Liège, Liège, Belgium \\ ${ }^{\mathrm{c}}$ Laboratory of Pharmacognosy, CIRM, Department of Pharmacy, University of Liège, Liège, Belgium
}

Received, February 3, 2010; Revised, June 30, 2010; Accepted, September 7, 2010; Published, September 10, 2010

\begin{abstract}
Purpose: Cholesterol is a major lipid constituent of biological membranes which could be included in cyclodextrin (CD) cavities. Solubilization and cell extraction of cholesterol have been previously performed in order to study its interaction with $\beta$-CD and methylated $\beta$-derivatives notably. The present work aims at confirming the formation of inclusion complexes between these CDs and cholesterol in order to understand their solubilization and cell extraction capacities. Methods: In this context, liquid-state NMR spectroscopy ( ${ }^{1} \mathrm{H}$ NMR studies and ROESY experiments) as well as theoretical studies (molecular modeling) have been performed. Results: Rather than preferential conformations, the spectroscopic studies showed us the possible interactions between cholesterol and dimethyl- $\beta-C D$, trimethyl $\beta-C D$, randomly methylated $\beta-C D$ or Crysmeb $^{\circledR}$. Weak interactions were detected using the latter one, confirming the advantage of the low substitution to decrease membrane loss of integrity and cytotoxicity. Molecular modeling studies should be used to determine which stoichiometry and conformations are energically more favorable. The semi-empirical AM1 level was used to investigate both 1:1 and 1:2 complexes whereas 1:1 complexes were also studied using minimal or double $\zeta$ basis sets. Four conformations for each 1:2 complexes have been envisaged and studied for the methylated CDs. Conclusions: These studies allowed us to confirm the interactions between cholesterol and $\beta$-CDs especially the methylated derivatives.
\end{abstract}

\section{INTRODUCTION}

Cyclodextrins (CDs) are water-soluble compounds containing a hydrophobic core able to solubilize non polar substances. Thus, they have been used as excipients to deliver hydrophobic drugs $(1,2)$. Cholesterol is a lipidic molecule, member of the sterol family. It is a major lipid constituent of biological membranes.

Due to their affinity for hydrophobic molecules, CDs may be able to extract membrane cholesterol which could explain the toxicity of some methylated derivatives $(3,4)$. Methylated derivatives are assumed to increase drug flux by altering barrier properties of the membrane through component extraction or fluidization (5).Their mechanism of action as absorption enhancing compounds (i.e. through the respiratory epithelium) may be also explained by their ability to transiently open/perturb tight junctions $(6,7)$.

In vitro, $\beta-\mathrm{CD}$ and its derivatives have a high affinity for sterols compared to other lipids and because of the relatively high specificity with cholesterol, it has been suggested that these compounds might be effective in modifying cholesterol metabolism in vivo (1). Therefore, they could act as potential pharmacological agents by influencing the development of the atherosclerotic plaque. CDs are currently used to modulate membrane cholesterol levels by depleting or loading them by the use of cholesterol-CD complexes (8). These molecules are tools to study specialized membrane microdomains called lipid rafts/caveolae because of their enrichment in cholesterol particularly (9). Specific molecules such as receptors are associated with these microdomains explaining their involvement in various cellular functions $(10,11)$. By interfering with these microdomains, CDs can lead to membrane modifications explaining why methyl- $\beta-C D$ is currently used to study cellular functions (12). Thus, reduction of cholesterol level interferes with many processes which involve rafts and could be applied for treating raft-related infections and diseases (13). Moreover, it has been shown that cholesterol depletion using methyl- $\beta-C D$ increases permeability of intestinal cells monolayers by displacing specific proteins from cholesterol rich

Corresponding Author: Géraldine Piel; Laboratory of Pharmaceutical Technology, University of Liège ; Belgium ; Email : geraldine.piel@ulg.ac.be 
domains associated with tight junctions (14-17).

In vitro studies using model membranes (unilamellar liposomes) have been performed and could be used to predict the effects of CDs on biological membranes (18-20). Among these, the interaction of cholesterol with CDs in aqueous solution was investigated quantitatively (phase solubility diagrams) and correlated with liposome loss of integrity $(19,21)$. Another method such as NMR spectroscopy (22) could be used to determine the interaction between $\mathrm{CDs}$ and cholesterol. Different authors already studied the interactions of cholesterol with $\beta-\mathrm{CD}$ and its dimethylated (Dimeb) and trimethylated (Trimeb) derivatives (23-25). In the present work, ${ }^{1} \mathrm{H}$ NMR and ROESY spectra were taken in the same conditions in order to compare complexes with Dimeb and Trimeb with the one obtained with the randomly methylated derivative (Rameb) and a low substituted derivative $\left(\mathrm{Crysmeb}^{\circledR}\right)$. Another mean to predict interactions are theoretical studies. Molecular modeling studies (AM1 calculations) were used to study different hostguest inclusion complexes (26-30). Such theoretical methods were used here to study cholesterol complexes with $\beta-\mathrm{CD}$ and its methylated derivatives.

\section{METHODS}

\section{Materials}

Dimethyl- $\beta$-cyclodextrin (Dimeb, D.S. 2.0), Kleptose $^{\circledR}$ Crysmeb (Crysmeb; D.S. 0.5) and randomly methylated $\beta$-cyclodextrin (Rameb; D.S. 1.8) were kindly donated by Cyclolab (Budapest, Hungary), Roquette Frères (Lestrem, France) and Wacker-Chemie GmbH (Munich, Germany) respectively. Trimethyl- $\beta$-cyclodextrin (Trimeb; D.S. 3.0), a Fluka product, and cholesterol were obtained from Sigma-Aldrich (Bornem, Belgium). Deuterium oxide (99.97\%) was purchased from Eur-isotop (Saint-Aubain, France). All other compounds were of analytical grade.

\section{Methods}

\section{NMR Spectroscopy}

\section{${ }^{1} \mathrm{H}$ NMR studies}

One-dimensional ${ }^{1} \mathrm{H}$ NMR spectra were recorded at $25{ }^{\circ} \mathrm{C}$ on a Bruker Avance 500 operating at a proton NMR frequency of $500.13 \mathrm{MHz}$ using a 5 $\mathrm{mm}$ probe and a simple pulse-acquire sequence. Acquisition parameters consisted of a spectral width of $10,333.6 \mathrm{~Hz}$, a $30^{\circ}$ pulse, an acquisition time of $3.17 \mathrm{sec}$ and a relaxation delay of $1 \mathrm{~s}$. For each sample, 128 scans were recorded. FIDs were Fourier transformed with $\mathrm{LB}=0.3 \mathrm{~Hz}$ and $\mathrm{GB}=$ 0 . The resonance due to residual solvent (HOD) was used as internal reference.

$\mathrm{CD}$ reference solutions were prepared by dissolving appropriate amounts of Dimeb, Trimeb, Crysmeb and Rameb directly in $700 \mu 1$ $\mathrm{D}_{2} \mathrm{O}$ in order to obtain concentrations around 50 $\mathrm{mM}$ (around 46, 51, 41 and $46 \mathrm{mg}$ respectively). Sample solutions were prepared by adding excess amounts of cholesterol to the $\mathrm{CD}$ solutions. The resulting suspensions were shaken at $25{ }^{\circ} \mathrm{C}$ during one hour and then filtered through a $0.4 \mu \mathrm{m}$ membrane filter. The cholesterol reference solution (around $11 \mathrm{mM}$ ) was prepared in DMSOd6.

Variation of ${ }^{1} \mathrm{H}$ NMR chemical shifts of $\mathrm{CD}$ protons $(\Delta \delta)$ caused upon complexation were calculated to confirm the interaction with cholesterol according to the following formula:

$$
\Delta \delta=\delta_{\text {(complexed state) }}-\delta_{(\text {free state) }}
$$

Where $\delta_{\text {(complexed state) }}$ corresponds to the chemical shifts values in the complexed state and $\delta_{\text {(free state) }}$ in the free state.

\section{ROESY Experiments}

Rotating-frame Overhauser Effect SpectroscopY (ROESY) spectra were acquired in the phase sensitive mode using the same spectrophotometer and Bruker standard parameters (pulse program roesyph). Each spectrum consisted of a matrix of 2K (F2) by 256 (F1) points covering a spectral width of $5122.9 \mathrm{~Hz}$. Spectra were obtained from the same sample solutions prepared for the ${ }^{1} \mathrm{H}$ NMR studies, using a spin-lock mixing time of $350 \mu \mathrm{s}$. Before Fourier transformation, the sine apodization function was applied in both dimensions. 32 scans were collected for each of the experiments.

\section{Molecular Modeling}

The geometries were fully optimized without any constraint by minimisation of the analytical gradient. The nature of the located critical points is determined by vibrational frequency calculation derived from the second derivative matrix. When all the eigenvalues of this Hessian matrix are 
positive, the energy is minimum in each direction associated to the variables. Nowadays, Austin Model 1 (AM1) calculations (31) can be run routinely, the time requested for a geometry optimization of around 250 atoms into 200 iterations being less than 2 hours. This semiempirical level is limited to the valence atomic orbitals (A.O) only and applies several approximations in the calculation of the bielectronic integrals. In the case of the complex between cholesterol and Crysmeb, the number of A.O is 560. The Hartree-Fock $a b$ initio level solves the Roothaan equation using a basis set which can be minimal or extended (double,

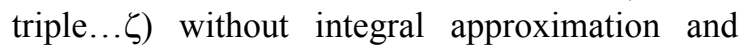
using non orthogonal functions. The $\zeta$ value accounts for how large the orbital is. With the MINI-1 basis set (32), the number of A.O grows up to 669 and the time requested is more than 2 cpu days on a 8 processors machine. The most interesting feature of the $a b$ initio level is the quality of the calculated geometry very often in good agreement with experimental data and also the estimation of reliable interaction energies (33). The upper step is to use a double $\zeta$ basis set with additional polarization functions as the 6$31 \mathrm{G}(\mathrm{d})$ basis set (34) and a energy function derived from the Density Functional Theory (DFT) as B3LYP (35). The basis set used 1229 functions and the geometry optimization time is more than $8 \mathrm{cpu}$ days on a 8 processors machine again for cholesterol and Crysmeb. This time becomes enormous for cholesterol-Dimeb complexes (more than 20 days) to solve the equations generated with 1954 functions.
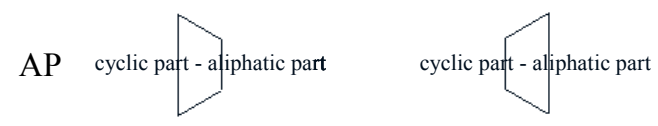

A
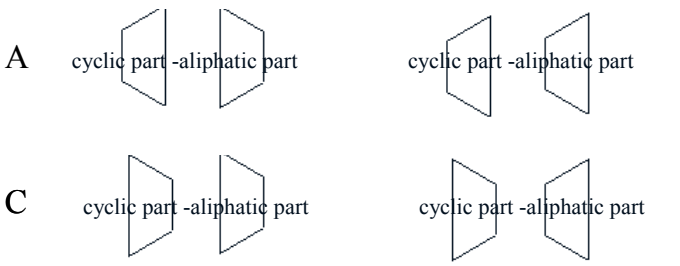

Figure.1. Schematic representations of the conformations envisaged for the $1: 1$ (AP and AS) and $1: 2$ complexes (A, B, C and D). AP: aliphatic chain of cholesterol is located towards the primary alcohol groups of the CD. AS: aliphatic chain of cholesterol is close to the secondary face. Four types of $1: 2$ complexes were investigated. A, B, C or D conformations depend the relative orientation of the CD cavities.
All the calculations have been performed using the Gaussian 03 suite of programs (36). Different softwares were used as X-Win 32, Molden and Mercury 2.2. to generate illustrations of the complexes.

Two types of 1:1 complexes were studied. The AP notation corresponds to the conformation where the aliphatic chain of cholesterol is located towards the primary alcohol groups of the CD while for the AS conformation, the chain is close to the secondary face. Four types of 1:2 complexes (A, B, C or D conformations) were investigated depending on the part of cholesterol which is included in the $C D$ cavity and on the relative orientation of the $C D$ cavities. Schematic representations of all the possible conformations are presented in Fig.1.

The atomic coordinates of the $\beta$-CD molecule (refcode POBRON of the Cambridge Structural Database) has been selected as starting geometry for a complete optimization of the isolated $\beta-C D$ (Fig.2). The methylated derivatives were built-up by adding methyl groups $\left(\mathrm{CH}_{3}\right)$ to $\beta$-CD on each glucopyranose units for Dimeb and Trimeb (respectively on O-2 and O-6 and O-2, O-3 and O-6 positions). Crysmeb which is methylated selectively at the secondary O-2 position was built-up by adding $4 \mathrm{CH}_{3}$ on this position for the $1,3,5$ and 7 glucose residues leading to a D.S. of approximatively 0.57 (close to the one proposed by Roquette). Concerning Rameb (D.S. 1.8), 13 substituents were added on the natural core namely $3 \mathrm{CH}_{3}$ on the $\mathrm{O}-2$ position for the 3,4 and 7 glucopyranose units, 3 groups on the O-3 for the 1,2 and 5 glucose residues and finally 7 on each O-6 position except for the last unit.

The calculation procedure is the following: starting from the optimized geometry of each complex, cholesterol and $\mathrm{CD}$ were reoptimized separately. This procedure allows the determination of consistent energetic data, as each relative energy is calculated by reference to the geometry of the complex (29).

\section{RESULTS}

\section{NMR Studies}

Atoms notations for cholesterol, according to Ravichandran (23), can be seen in Figure 3 which shows the $500 \mathrm{MHz}{ }^{1} \mathrm{H}$ NMR spectrum of cholesterol in DMSO-d6 up to $6.0 \mathrm{ppm}$. Due to the different media used for the reference and sample solutions, no shifts variations were calculated upon complexation for cholesterol. 

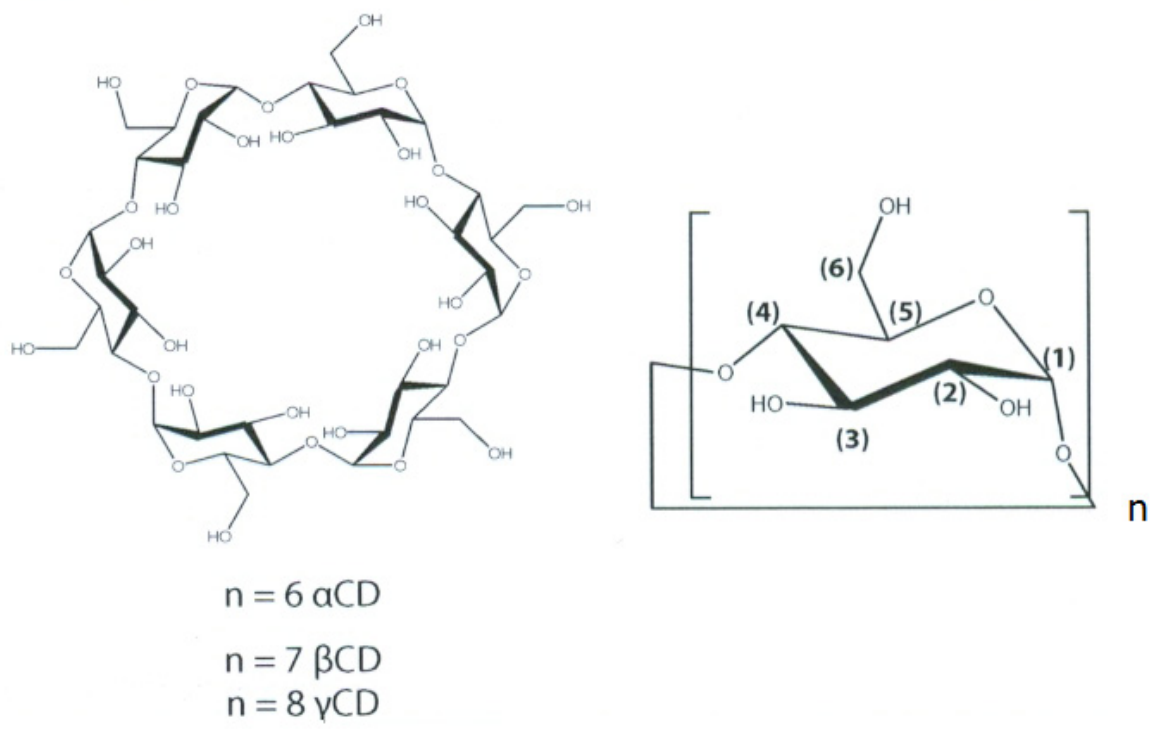

Figure.2. Chemical structure of natural cyclodextrins and of $\alpha$-D-glucopyranose unit (37)

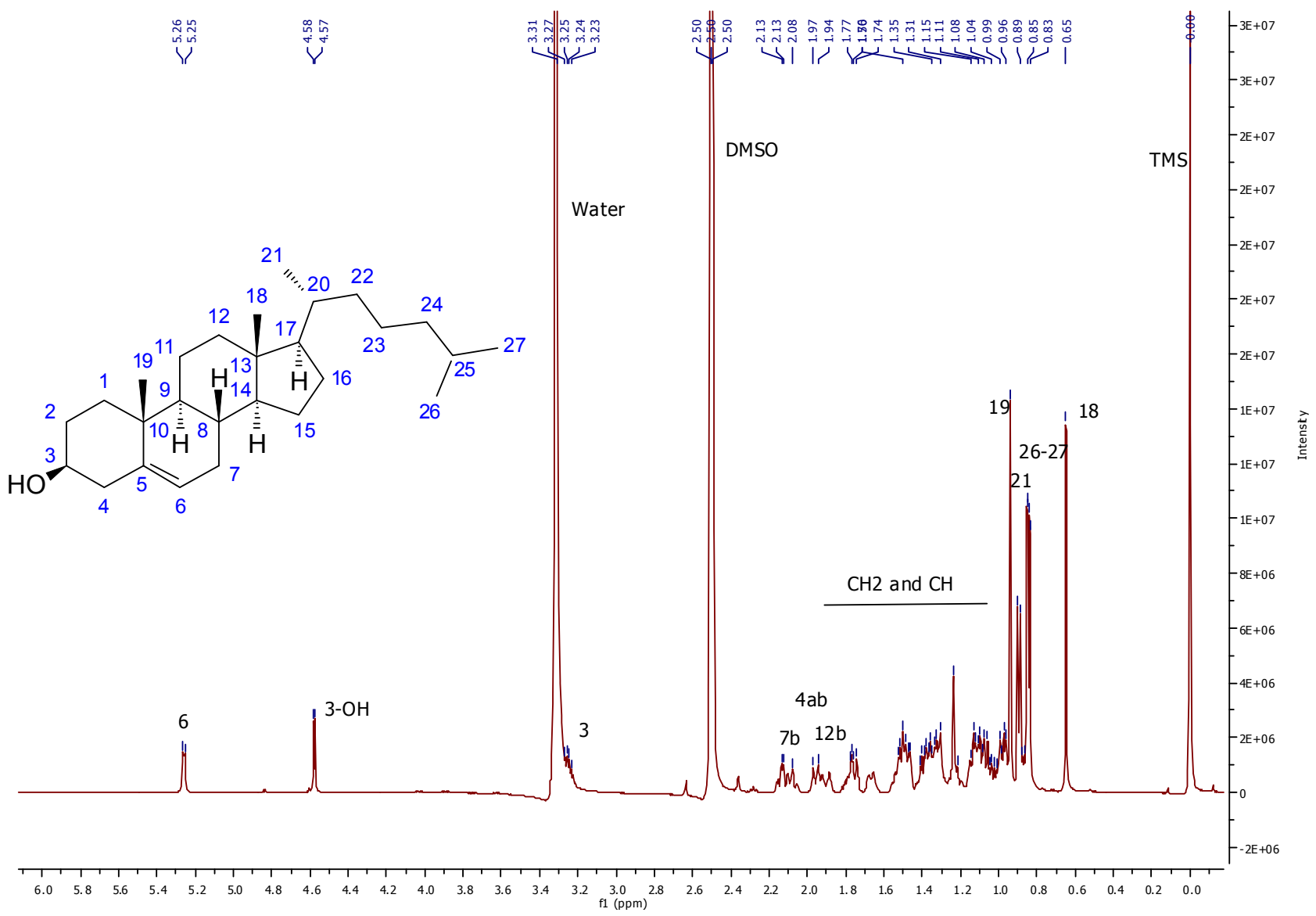

Figure 3. ${ }^{1} \mathrm{H}$ NMR spectrum of cholesterol in DMSO and atoms notations 


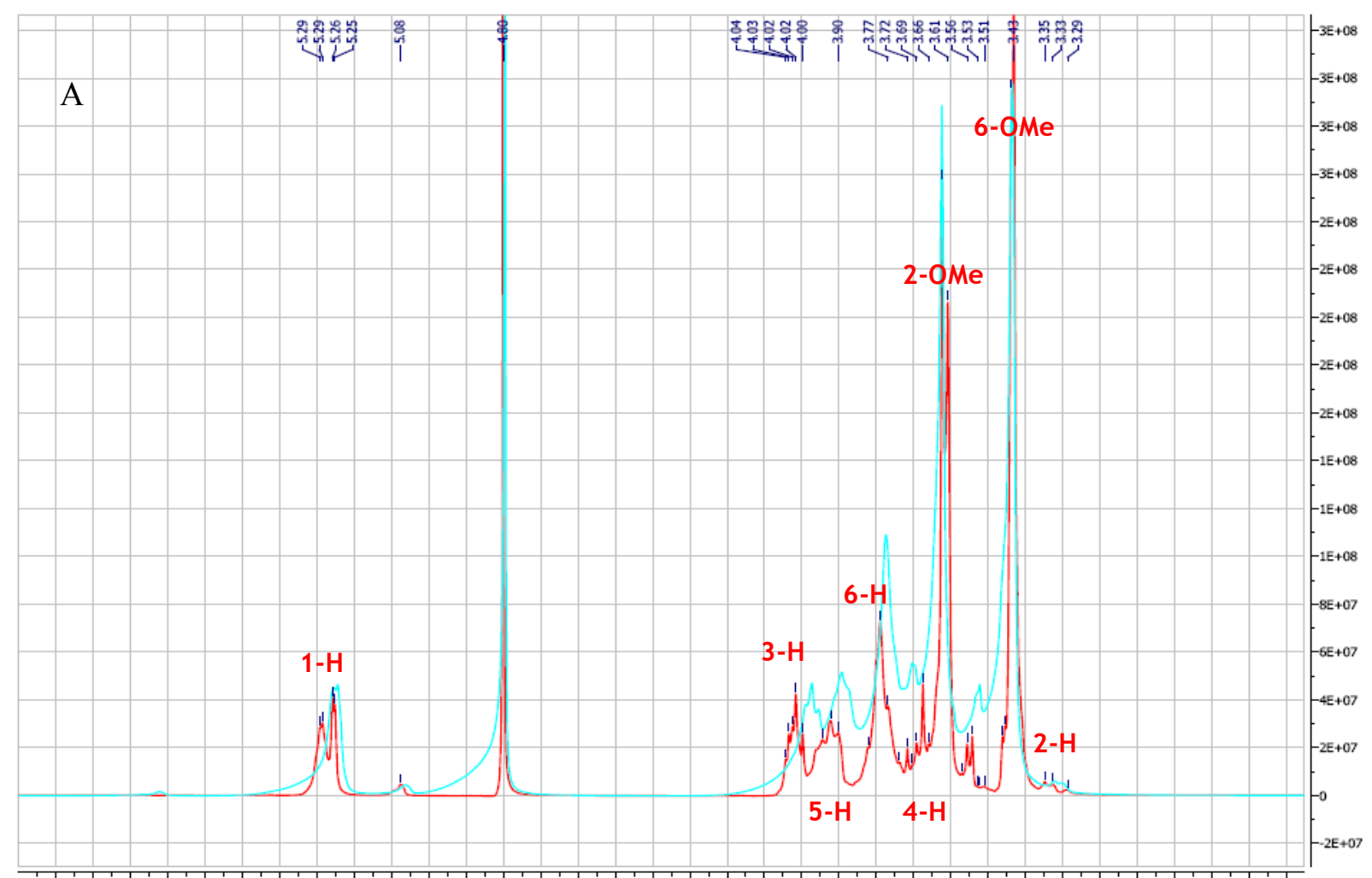

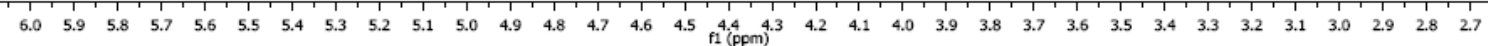

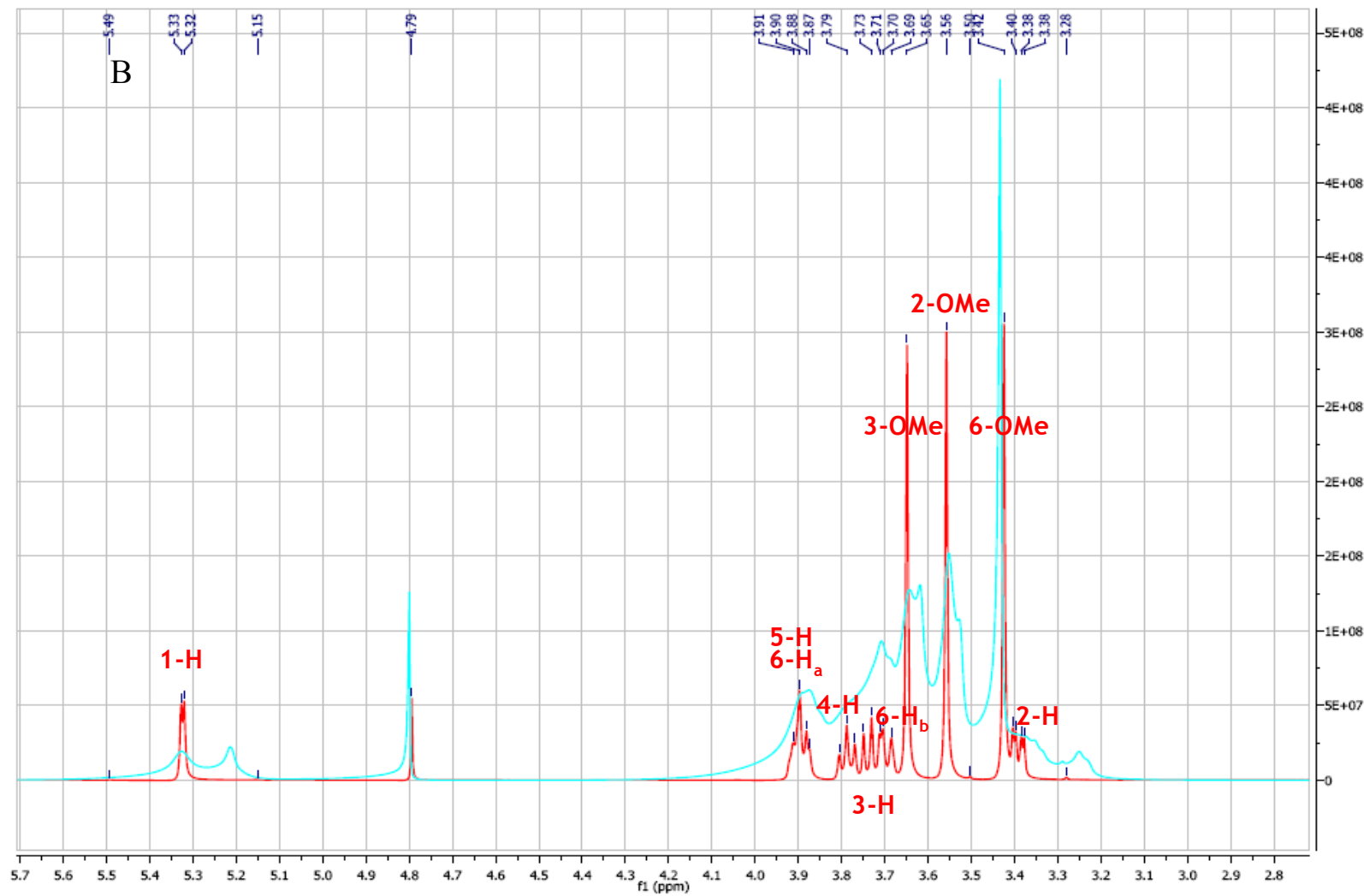




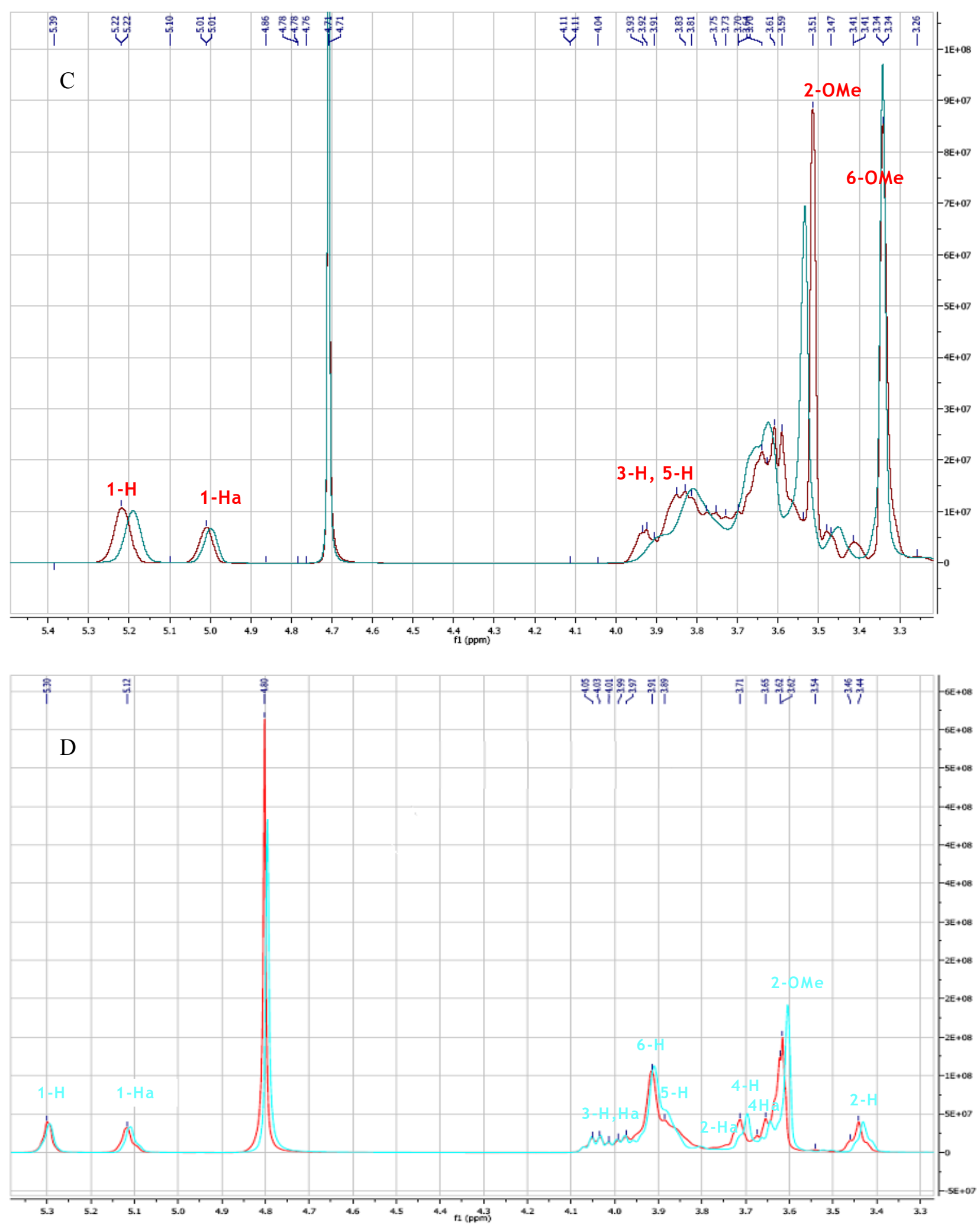

Figure 4. Partial ${ }^{1} \mathrm{H}$ NMR spectra of the cholesterol-CD complex solution (blue) and of the CD solution in $\mathrm{D}_{2} \mathrm{O}$ with assignment of the signals of the CD (red): Dimeb (A), Trimeb (B), Rameb (C), Crysmeb (D) 
The ${ }^{1} \mathrm{H}$ NMR spectra between 2.7 and 6.1 ppm of Dimeb in $\mathrm{D}_{2} \mathrm{O}$ alone (reporting the protons) or associated in the complex with cholesterol are shown in Fig. 4A. reports the differences between ${ }^{1} \mathrm{H}$ NMR chemical shifts values of Dimeb protons in the complexed and free state $(\Delta \delta)$. Proton signals due to $3-\mathrm{H}$ shifted upfield prominently followed by the signals due to $5-\mathrm{H}$ as it has already been shown (24). Because these protons are located inside (Fig. 1) the CD cavity, their shifts suggest that cholesterol is included inside the Dimeb. The interactions are also confirmed in the two-dimensional ROESY experiment as correlation spots are clearly detectable between cholesterol and the CD inner protons (especially $3-\mathrm{H})(5 \mathrm{~A})$.

Also, it is considered that the shifts variations of 2-OMe and 6-OMe (Table 1) occur because they come into contact with another methyl of a second CD confirming the formation of 1:2 complexes (24). To summarize, as shown in Fig. $5 \mathrm{~A}$, cross peaks connecting the $3-\mathrm{H}, 5-\mathrm{H}$ and $6-\mathrm{H}$ of Dimeb, as well as 2-OMe and 6-OMe, to the $18-\mathrm{CH}_{3}, 26-\mathrm{CH}_{3}, 27-\mathrm{CH}_{3}, 21-\mathrm{CH}_{3}$ and/or $19-\mathrm{CH}_{3}$ can be observed. All the results obtained are mostly in accordance with those of Nishijo et al. (24) and confirm the formation of inclusion complexes. To interpret the results in two dimensions, mostly the protons corresponding to the aliphatic chain of cholesterol have been considered. Interpretations concerning the double bond and $\mathrm{CHOH}$ (cyclic part) would be difficult because of the localization of these signals in the same area (3.2 to $5.5 \mathrm{ppm}$ ) of the spectrum corresponding to the ones of the $\mathrm{CD}$ and water (Fig. 3 and 4A).

Table 1. Variation of ${ }^{1}$ H NMR chemical shifts (ppm) of Dimeb or Crysmeb protons in the presence of cholesterol

\begin{tabular}{lll}
\hline Protons & $\Delta \delta$ Dimeb & $\Delta \delta$ Crysmeb \\
\hline H-1 & -0.02 & +0.01 \\
$\mathrm{H}-2$ & -0.02 & +0.01 \\
$\mathrm{H}-3$ & -0.06 & 0 \\
$\mathrm{H}-4$ & +0.04 & +0.01 \\
$\mathrm{H}-5$ & -0.03 & 0 \\
$\mathrm{H}-6$ & -0.02 & 0 \\
\hline$\Delta \delta=\delta$ & \\
\hline
\end{tabular}

The protons of Trimeb alone were assigned by comparison to the spectrum obtained by Nishijo et al. (25) (Fig.4B). As shown in the figure, the ${ }^{1} \mathrm{H}$ NMR spectrum of Trimeb in presence of cholesterol is deformed when compared to the one of Trimeb alone.
Attributions are thus difficult for Trimeb in presence of cholesterol. It was therefore not possible to calculate proton shifts variations in this case. The broad deformed signals could be explained by the superposition of complexed species and uncomplexed one because of slow exchange rate between complexed species and the free one as suggested by the group of Nishijo (25). However, cholesterol seems to interact with Trimeb as shown on the ROESY spectrum of the mixture showing cross peaks between protons of cholesterol and methyl groups (3-OMe and 6$\mathrm{OMe}$ ) of the $\mathrm{CD}$ (Fig 5B). The formation of inclusion complexes between the two molecules cannot be excluded. Indeed, correlation spots could probably be attributed to an interaction with the inner protons which are difficult to assign because of broad deformed signals (Fig 5B).

NMR studies on Rameb are difficult because it is not a single pure compound, but rather a mixture of randomly methylated molecules of $\beta$ CD (38). Only partial proton attributions could be done by comparison to the spectrum obtained with the well characterized Dimeb. The presence of cholesterol is related to an upfield shift of 2OMe $(+0.02 \mathrm{ppm})$ which seems to suggest its involvement in the interactions while no shift appeared for 6-OMe (Fig. 4C). Concerning the protons of the inner cavity, 5-H shifted downfield in the presence of cholesterol (-0.02 ppm). Data on $3-\mathrm{H}$ were inconclusive. So, based on these data, only limited conclusions can be made on the involvement of the CD protons. On the ROESY spectrum (Fig 5C), correlation spots between a couple of protons of cholesterol and 2-OMe but also 6-OMe can be seen confirming the implication of the latter one in the interactions. From the two types of NMR experiments, it is possible to assume the interactions of cholesterol with the methyl groups of Rameb. Despite the difficulty to assign the methine protons of the $\mathrm{CD}$ after complexation, the interactions shown in Fig. $5 \mathrm{C}$ probably involve $\mathrm{CD}$ protons such as $3-\mathrm{H}$ or $5-\mathrm{H}$.

In Fig. 4D, protons were assigned for the onedimensional spectrum obtained with the Crysmeb solution in reference with the work of Bakkour (39). As shown in figure 4D and Table 1, no significant shifts variations were evaluated for the cholesterol-Crysmeb solution. However, weak interactions were detected in two dimensions between the $18-\mathrm{CH}_{3}, 26-\mathrm{CH}_{3}, 27-\mathrm{CH}_{3}, 21-\mathrm{CH}_{3}$ and $19-\mathrm{CH}_{3}$ of cholesterol and $3-\mathrm{H}, 5-\mathrm{H}$ or $6-\mathrm{H}$ of the $\mathrm{CD}$ (Fig. 5D) confirming the formation of cholesterol-Crysmeb inclusion complexes. 


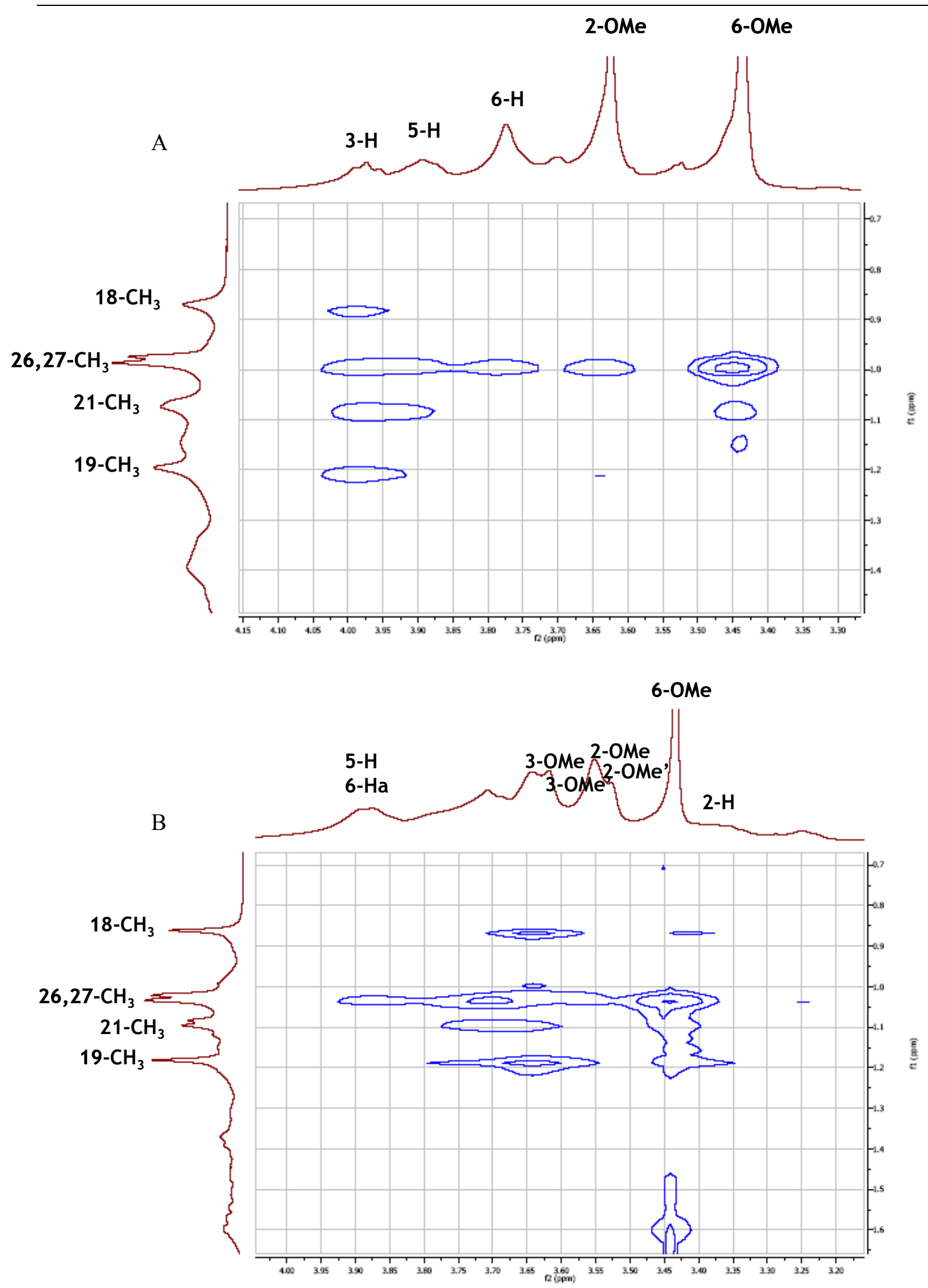



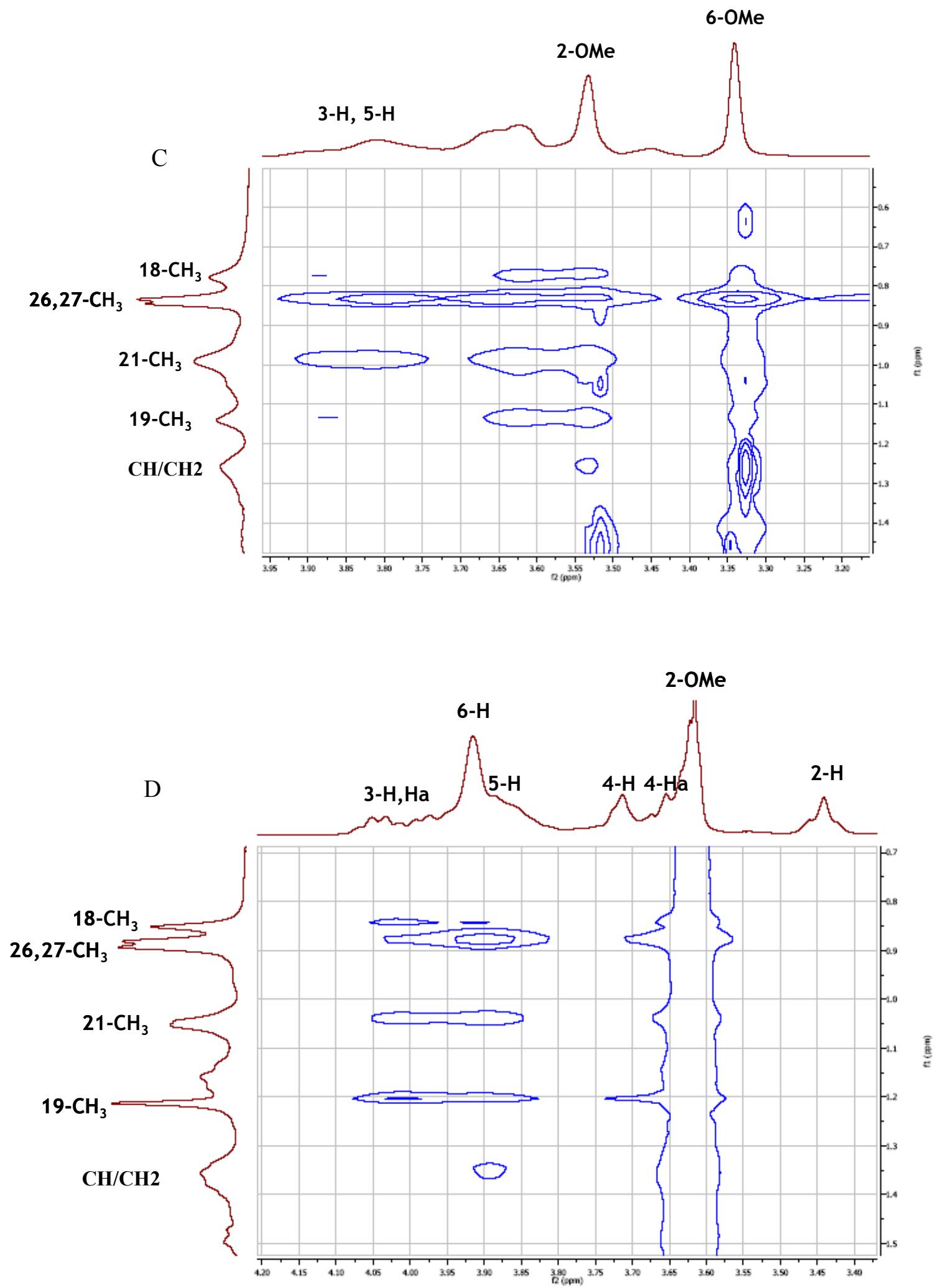

Figure 5. Two-dimensional ROESY spectrum of a solution containing CD (50 mM) saturated with cholesterol: Dimeb (A), Trimeb (B), Rameb (C), Crysmeb (D). 
The weakness of the interactions observed could be due to the lower solubilization of cholesterol with Crysmeb at equivalent concentration of 50 $\mathrm{mM}$ leading to weaker detectable interactions than with other studied CDs.

\section{Molecular Modeling}

As previously determined, phase solubility diagrams of cholesterol with Dimeb, Trimeb, Rameb and Crysmeb are of the Ap type following the Higuchi and Connors classification (21). Therefore, in aqueous solutions, two types of complexes having molar ratios of $1: 1$ and $1: 2$ are possible. In the case of cholesterol with Dimeb or Trimeb, 1:2 complexes are formed more easily. As a matter of fact, $\mathrm{K}_{1: 2}$ values calculated by Nishijo $(24,25)$ are higher than $K_{1: 1}$ values (at $25^{\circ} \mathrm{C}, \mathrm{K}_{1: 2 \text {-Dimeb }}=56,800 \mathrm{M}^{-1}>>\mathrm{K}_{1: 1 \text {-Dimeb }}=109$ $\mathrm{M}^{-1} ; \mathrm{K}_{1: 2 \text {-Trimeb }}=75,500 \mathrm{M}^{-1}>>\mathrm{K}_{1: 1-\text { Trimeb }}=77 \mathrm{M}^{-}$ $\left.{ }^{1}\right)$. Molecular modeling should be used here to determine which type of complexes and conformations are more favorable. Concerning $\beta$ $\mathrm{CD}$, for which no increase in cholesterol aqueous solubility could be determined, only the 1:1 complexes were investigated.

Results are presented as energetic outcomes expressed as interaction, deformation and complexation energies (Fig. 6). The interaction energy is defined as the difference between the energy of the complex and the sum of the energies of both partners at their complex geometry. The deformation energy is determined by the difference between the energy of one of the partners of the complex at its equilibrium geometry (which is obtained by reoptimization of the one found in the complex) and its energy at the complex geometry. The complexation energy is the difference between the energy of the complex and the sum of the energy of each partner at their respective equilibrium geometry.

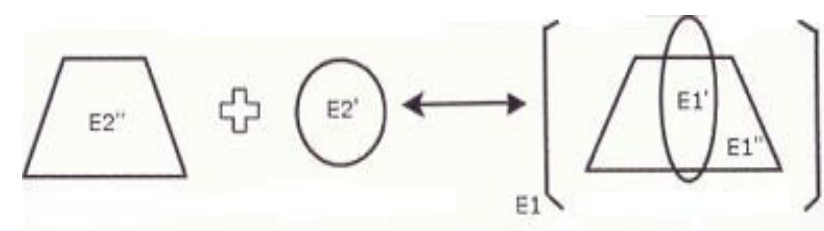

$$
\begin{gathered}
\text { Optimized complex } \\
\text { Interaction energy: E1 - (E1' + E1', }) \\
\text { Deformation energy: E1' - E2' or E1', - E2', } \\
\text { Complexation energy: E1 - (E2' + E2'’) }
\end{gathered}
$$

Figure.6. Schematic representation of the interaction, deformation and complexation energies

The results obtained for the 1:1 complexes with AM1 calculations are given in Table 2. The interaction energies are always favorable although they are relatively low compared to other studied complexes especially in the case of miconazole (26). Complexation energies values are negative for the complexes with $\beta-\mathrm{CD}$ and Crysmeb which means that their formation is energetically favorable. On the contrary the high substituted methylated CDs show positive values suggesting lower probabilities for 1:1 complexes. The deformation of cholesterol is weaker than the deformation of CDs. This is reasonably due to the rigidity of the four-ringed backbone of this molecule. Dimeb and Trimeb exhibit more deformability upon complexation as suggested by the high values obtained compared to the other CDs. The highest deformation energies for cholesterol are generally obtained with Trimeb which means that complex formation should be

\begin{tabular}{|c|c|c|c|c|c|c|c|c|c|c|}
\hline \multirow{2}{*}{$\begin{array}{l}\text { CD } \\
\text { Conformation }\end{array}$} & \multicolumn{2}{|c|}{$\beta-C D$} & \multicolumn{2}{|c|}{ Dimeb } & \multicolumn{2}{|c|}{ Trimeb } & \multicolumn{2}{|c|}{ Rameb } & \multicolumn{2}{|c|}{ Crysmeb } \\
\hline & $\mathbf{A P}$ & AS & AP & AS & $\mathbf{A P}$ & AS & $\mathbf{A P}$ & AS & $\mathbf{A P}$ & AS \\
\hline Interaction en. & -5.182 & -5.788 & -4.802 & -3.536 & -5.538 & -4.943 & -4.921 & -4.214 & -7.046 & -5.074 \\
\hline $\begin{array}{l}\text { Deformation en. } \\
-\quad \text { Cholesterol } \\
-\quad \text { CD }\end{array}$ & $\begin{array}{l}-0.598 \\
-1.330\end{array}$ & $\begin{array}{l}-0.358 \\
-1.169\end{array}$ & $\begin{array}{l}-0.918 \\
-6.943\end{array}$ & $\begin{array}{l}-1.110 \\
-7.987\end{array}$ & $\begin{array}{l}-2.241 \\
-3.621\end{array}$ & $\begin{array}{l}-3.629 \\
-7.732\end{array}$ & $\begin{array}{l}-2.403 \\
-3.687\end{array}$ & $\begin{array}{l}-1.088 \\
-3.554\end{array}$ & $\begin{array}{l}-1.309 \\
-2.298\end{array}$ & $\begin{array}{l}-0.413 \\
-3.424\end{array}$ \\
\hline Complexation en. & -3.254 & -4.261 & 3.058 & 5.571 & 0.325 & 6.418 & 1.169 & 0.429 & 3.440 & -1.237 \\
\hline
\end{tabular}
difficult.

Table 2. Interaction, deformation and complexation energies in Kcal/mole for 1:1 complexes with the reference to reoptimized CDs and cholesterol (AM1 calculations) 
Table 3. Interaction, deformation and complexation energies in Kcal/mole for $1: 1$ complexes with the reference to reoptimized CDs and cholesterol (MINI-1 calculations)

\begin{tabular}{|c|c|c|c|c|c|c|c|c|c|c|}
\hline \multirow{2}{*}{$\begin{array}{l}\text { CD } \\
\text { Conformation }\end{array}$} & \multicolumn{2}{|c|}{$\beta-C D$} & \multicolumn{2}{|c|}{ Dimeb } & \multicolumn{2}{|c|}{ Trimeb } & \multicolumn{2}{|c|}{ Rameb } & \multicolumn{2}{|c|}{ Crysmeb } \\
\hline & $\mathbf{A P}$ & AS & AP & AS & $\mathbf{A P}$ & AS & AP & AS & $\mathbf{A P}$ & AS \\
\hline Interaction en & 4.991 & 2.437 & 0.102 & 6.467 & 4.111 & 4.802 & 5.711 & 6.024 & -0.074 & 0.197 \\
\hline \multicolumn{11}{|l|}{ Deformation } \\
\hline - Cholesterol & -0.281 & -0.505 & -0.257 & -1.283 & -2.329 & -0.961 & -3.357 & -0.554 & -0.092 & -0.401 \\
\hline$-\quad C D$ & -1.189 & -0.406 & -1.253 & -4.500 & -7.892 & -11.004 & -6.428 & -8.159 & -0.261 & -0.841 \\
\hline Complexation en & 6.461 & 3.348 & 1.612 & 12.250 & 14.332 & 16.766 & 15.496 & 14.737 & 0.280 & 1.439 \\
\hline
\end{tabular}

For all the five 1:1 complexes, the ab initio MINI1 calculations have been performed and the results are given in Table 3. What is surprising is to obtain non stabilizing interaction energies by opposite to the AM1 calculations (Table 2). With the MINI-1 basis set, the interatomic distances are overestimated and this feature could have a great incidence on the interactions occuring in a so closed environment. In order to refine the results, the geometries of the complexes with each CDs except Trimeb have been optimized at the B3LYP/6-31G(d) level. The 8 interaction energies are generally in good agreement with the AM1 results (Table 4).

This result is satisfactory. Nevertheless, with regard to the MINI-1 calculations, the question remains open concerning the ability of AM1 to describe a very dense H-bond network. Two additional rather fast computations (energy only without minimization of the gradient) have been run using the DFT/6-31G(d) level at the AM1 and the MINI-1 geometries noted in Table 4 B3LYP//AM1 and B3LYP//MINI-1. They confirm that AM1 is not very efficient to describe H-bond network in inclusion complexes. Moreover, the good agreement between B3LYP//MINI-1 results and B3LYP//B3LYP ones could suggest a significant part of the correlation energy in such complexes which is taken into account in DFT and not at the HartreeFock level.

Table 4. Comparison of the interaction energies in $\mathrm{Kcal} / \mathrm{mole}$ for the 1:1 complexes obtained with different calculation methods.

\begin{tabular}{lcccccccccc}
\hline CD & \multicolumn{2}{c}{$\boldsymbol{\beta}-\mathbf{C D}$} & \multicolumn{2}{c}{ Dimeb } & \multicolumn{2}{c}{ Trimeb } & \multicolumn{2}{c}{ Rameb } & \multicolumn{2}{c}{ Crysmeb } \\
Conformation & AP & AS & AP & AS & AP & AS & AP & AS & AP & AS \\
\hline AM1//AM1 & -5.182 & -5.788 & -4.802 & -3.536 & -5.538 & -4.943 & -4.921 & -4.214 & -7.046 & -5.074 \\
MINI-1/MINI-1 & 4.991 & 2.437 & 0.102 & 6.467 & 4.111 & 4.802 & 5.711 & 6.024 & -0.074 & 0.197 \\
B3LYP//B3LYP & 0.124 & -3.189 & -5.607 & -1.130 & - & - & -4.871 & -2.647 & -3.998 & -6.167 \\
B3LYP//AM1 & 10.529 & 7.838 & 11.923 & 15.450 & 11.246 & 17.155 & 15.529 & 15.668 & 10.018 & 7.904 \\
B3LYP//MINI-1 & -1.856 & -4.634 & -5.161 & -1.589 & -2.965 & -2.160 & -2.187 & -3.342 & -3.802 & -6.097 \\
\hline
\end{tabular}


A

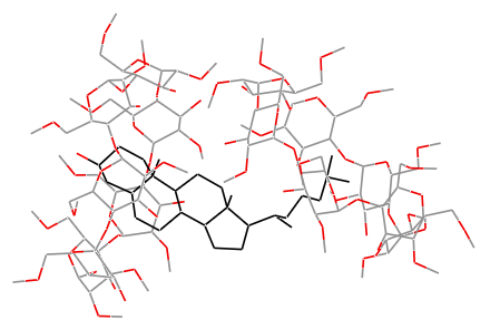

$\mathrm{C}$

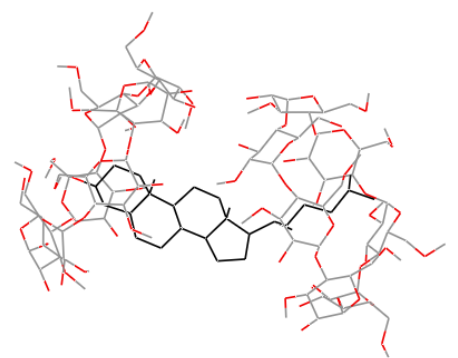

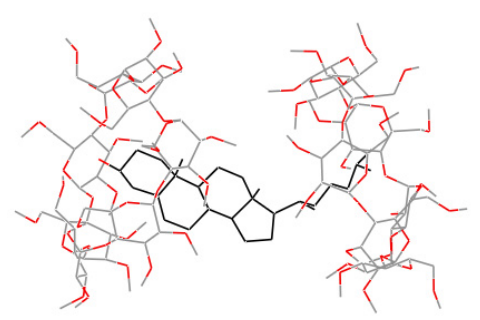

B

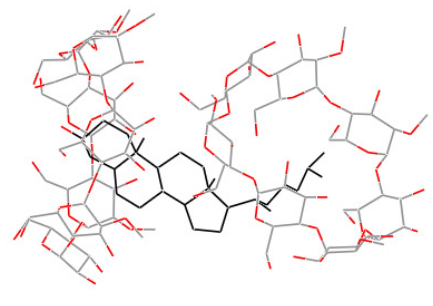

D

Figure 7. Structures of the most favorable 1:2 complexes (A: Dimeb; B: Trimeb; C: Rameb and D: Crysmeb)

This could explain the differences between MINI1//MINI-1 and B3LYP//MINI-1 values. It remains that AM1//AM1 seems to give reliable interaction energies in rather good accordance with the most elaborate results B3LYP//B3LYP else if the poor description of the H-bond network effect in the complex was counterbalanced by the same poor description in the cyclodextrin alone giving rise to a cancellation of errors. Nevertheless, for the first time, the present study clearly points out the need to use more elaborate method than the semiempirical ones in order to obtain a good geometry description of inclusion complexes with cyclodextrins. More in-depth analysis is actually under investigation in particular the size of the basis set in order to have a reasonable compromise between quality and cpu time.

Because increasing the size of systems renders the use of basis sets such as the MINI-1 prohibitively expensive and time-consuming only the semi-empirical AM1 calculations were carried out concerning the 1:2 complexes. Results for 1:2 complexes with Dimeb, Trimeb, Rameb and Crysmeb are presented in Table 5. The interaction energies calculated in these cases are really higher compared to the 1:1 complexes (and values differ significantly between the conformations or $\mathrm{CD}$ envisaged). The lower interaction energies were obtained for complexes with Trimeb whereas the highest values were obtained with Crysmeb. The complexation energies are stabilizing for all the conformations envisaged with Dimeb, Rameb and Crysmeb. For Trimeb, the $\mathrm{C}$ and $\mathrm{D}$ conformations are not favorable. With each $\mathrm{CD}$, except for
Crysmeb, higher negative values were obtained with the A conformation suggesting higher probability for this one. For Crysmeb, the B conformation is the most favorable followed by the A, D and then C. In Fig. 7, the structures for the most favorable 1:2 complexes are represented. The complexation energies obtained for the 1:2 complexes with the methylated derivatives are always more favorable than those obtained for the 1:1 complexes, allowing to confirm the higher probability for these stoichiometries.

\section{DISCUSSION}

It is well known that the native $\beta$-CD exhibits poor water solubility which could explain the poor solubility of the cholesterol- $\beta-\mathrm{CD}$ complex in water (23). As a consequence, $\beta$-CD was not able to dissolve detectable amounts of cholesterol, as shown with the phase-solubility diagram in the previous study (21). This CD was thus not used in our NMR experiments performed in deuterated water. However, the very low concentrations of $\beta$ CD used in cellular culture allowed extracting relatively high amounts of cholesterol from cell membranes (4). Moreover, the production of the low-cholesterol butter commercialized in Belgium under the tradename "Balade ${ }^{\circledR}$ implies the use of $\beta-C D$ in the manufacturing process to extract cholesterol $(40,41)$. This suggested the possibility even for this CD to interact with cholesterol. Molecular modeling reinforced this hypothesis as complexation energies calculated at the AM1 level are favorable (Table 2). 


\begin{tabular}{|c|c|c|c|c|}
\hline Conformation & $\mathbf{A}$ & B & $\mathrm{C}$ & D \\
\hline Interaction en. & -16.164 & -13.458 & -16.893 & -10.544 \\
\hline \multicolumn{5}{|l|}{ Deformation en. } \\
\hline - Dimeb 1 cyc 1. & -5.093 & -3.102 & -3.891 & -0.897 \\
\hline - cholesterol & -2.253 & -2.581 & -3.222 & -1.862 \\
\hline - Dimeb 2_alpha & -0.945 & -1.703 & -4.841 & -1.287 \\
\hline Complexation en. & -7.872 & -6.073 & -4.939 & -6.499 \\
\hline Interaction en. & -11.441 & -9.632 & -6.253 & -10.733 \\
\hline \multicolumn{5}{|l|}{ Deformation en. } \\
\hline - Trimeb 1_cyc1. & -0.823 & -1.144 & -10.975 & -8.573 \\
\hline - cholesterol & -0.950 & -0.598 & -2.672 & -1.983 \\
\hline - Trimeb 2_alpha & -0.391 & -1.733 & -0.252 & -2.431 \\
\hline Complexation en. & -9.277 & -6.158 & 7.645 & 2.253 \\
\hline Interaction en. & -17.018 & -12.705 & -11.473 & -10.922 \\
\hline \multicolumn{5}{|l|}{ Deformation en. } \\
\hline - Rameb 1_cyc1. & -2.198 & -0.872 & -1.619 & -0.980 \\
\hline - cholesterol & -2.420 & -1.075 & -1.106 & -2.822 \\
\hline - Rameb 2_alpha & -0.578 & -1.139 & -0.469 & -1.657 \\
\hline Complexation en. & -11.822 & -9.618 & -8.279 & -5.463 \\
\hline Interaction en. & -12.946 & -18.706 & -12.067 & -17.196 \\
\hline \multicolumn{5}{|l|}{ Deformation en. } \\
\hline - Crysmeb 1_cyc1. & -0.824 & -1.442 & -1.084 & -3.756 \\
\hline - cholesterol & -0.855 & -1.252 & -1.658 & -3.060 \\
\hline - Crysmeb 2_alpha & -1.050 & -2.410 & -4.778 & -0.566 \\
\hline Complexation en. & -10.217 & -13.602 & -4.547 & -9.814 \\
\hline
\end{tabular}

$\beta-\mathrm{CD}$ is thus able to interact with cholesterol, forming insoluble or very low soluble complexes. In the chosen conditions, the present studies, as well as phase-solubility diagrams, did not allow us to elucidate which type of stoichiometry should be the most probable with $\beta$-CD.

${ }^{1} \mathrm{H}$ NMR and ROESY experiments enabled to investigate the interactions between cholesterol and four methylated $\beta$-CDs substituted in various ways. These spectroscopic studies showed us the possibility of an inclusion rather than preferential conformations. The high substituted Dimeb (D.S. 2) and Rameb (D.S. 1.8) are efficient cholesterol solubilizers or extractors from cell membranes. We have previously shown that this could be responsible of their destructive effect on liposomes and of their cytotoxicity $(4,21)$. The interactions were confirmed by spectroscopic studies as shown on the ROESY spectra. In the case of Dimeb, it was possible from the ${ }^{1} \mathrm{H}$ NMR spectrum to calculate upfield shifts of the inner cavity protons which confirm the inclusion. Finally, as suggested by molecular modeling at the AM1 level, 1:1 complexes with these CDs are not favorable while each 1:2 conformations are possible.

In cell culture, Trimeb showed an unexpected behaviour as it was not able to extract high amounts of cholesterol despite its good solubilization properties $(4,21)$. In membranes, cholesterol is associated with other lipids for which it can have an affinity and it is not as free 
as in solution. Using cholesterol containing liposomes, Trimeb had already shown lower destructive effect on the membrane integrity than CDs having similar dissolution ability (with D.S. around 2) (4). Biological membranes are even more complicated than the simplified liposomal models and the interactions could be more difficult due to the steric bulk of this molecule. Deformation energies calculated when using Trimeb were generally high which supports this suggestion. Moreover, only two of all the complexes conformations envisaged with this CD gave complexation energies favorable which could explain its difficulty to form complexes and to extract cholesterol. Another explanation could come from the ${ }^{1} \mathrm{H}$ NMR studies. As suggested by Nishijo et al. (25), the spectrum obtained upon complexation could be due to slow exchange rate between complexed species and the free molecules.

The results obtained with the spectroscopic studies confirm the lower affinity for the lipidic molecule when using the low substituted derivative Crysmeb as weaker interactions have been observed. This was already evaluated in vitro on cell membranes (4) and by phase solubility diagrams (21). In this last study, a 50 $\mathrm{mM}$ Crysmeb solution allowed the solubilization of very low concentrations of cholesterol (3.5 $\mathrm{mM}$ ) compared to the results obtained with the other methylated CDs (Dimeb : $11.15 \mathrm{mM}$, Rameb : $12.5 \mathrm{mM}$, Trimeb : $13.1 \mathrm{mM}$ ). As ${ }^{1} \mathrm{H}$ NMR spectra are measured in deuterated water, similar solubilization capacities as in aqueous solutions should be obtained. The lower solubilization of cholesterol has been correlated with good liposome membrane integrity in presence of Crysmeb solutions (21). The better cell viability after contact with Crysmeb solutions has been attributed to lower cholesterol extraction or solubilization $(4,7)$. However, at the AM1 level the highest interaction or complexation energies were generally obtained with this $\mathrm{CD}$ for $1: 2$ complexes as well as for 1:1 complexes.

As a conclusion, these studies allowed us to confirm the interactions between cholesterol and $\beta$-CDs especially the methylated derivatives.

\section{ACKNOWLEDGEMENTS}

M. Frédérich is senior research associate of the Fonds de la Recherche Scientifique (FRS-FNRS). G. Dive is research associate of the FRS-FNRS. $\mathrm{He}$ thanks the FRS-FNRS for the financial support of the high performance computing systems installed in Liège and Louvain-la-Neuve and also the Interuniversity Poles of Attraction initiated by the belgian state PAI/6-19 for financial support.

\section{REFERENCES}

1. Kilsdonk E.P., Yancey P.G., Stoudt G.W., Bangerter F.W., Johnson W.J., Phillips M.C., Rothblat G.H. Cellular cholesterol efflux mediated by cyclodextrins. J. Biol. Chem., 1995; 270:17250-17256.

2. Yancey P.G., Rodrigueza W.V., Kilsdonk E.P., Stoudt G.W., Johnson W.J., Phillips M.C., Rothblat G.H. Cellular cholesterol efflux mediated by cyclodextrins. Demonstration of kinetic pools and mechanism of efflux. J. Biol. Chem., 1996; 271:16026-16034.

3. Leroy-Lechat F., Wouessidjewe D., Andreux J.-P., Puisieux F., Duchêne D. Evaluation of the cytotoxicity of cyclodextrins and hydroxypropylated derivatives. Int. J. Pharm., 1994; 101:97-103.

4. Castagne D., Fillet M., Delattre L., Evrard B., Nusgens B., Piel G. Study of the cholesterol extraction capacity of $\beta$-cyclodextrin and its derivatives, relationships with their effects on endothelial cell viability and on membrane models. J. Incl. Phenom. Macrocycl. Chem., 2009; 63:225-231.

5. Loftsson T., Vogensen S.B., Brewster M.E., Konradsdottir F. Effects of cyclodextrins on drug delivery through biological membranes. J. Pharm. Sci., 2007; 96:2532-2546.

6. Marttin E., Verhoef J.C., Merkus F.W.H.M. Efficacy, safety and mechanism of cyclodextrins as absorption enhancers in nasal delivery of peptide and protein drugs. J. Drug Target., 1998; 6:17-36.

7. Belhadj Salem L., Bosquillon C., Dailey L.A., Delattre L., Martin G.P., Evrard B., Forbes B. Sparing methylation of $\beta$-cyclodextrin mitigates cytotoxicity and permeability induction in respiratory epithelial cell layers in vitro. J. Control. Release, 2009; 136:110-116.

8. Christian A.E., Haynes M.P., Phillips M.C., Rothblat G.H. Use of cyclodextrins for manipulating cellular cholesterol content. J. Lipid Res., 1997; 38:2264-2272.

9. Castagne D., Evrard B., Nusgens B., Piel G. Effect of $\beta$-cyclodextrin and its derivatives on caveolae disruption, relationships with their cholesterol extraction capacities. J. Incl. Phenom. Macrocycl. Chem., 2009; doi:10.1007/s10847-009-9718-3 (Online first). 
10. Brown D.A., London E. Functions of lipid rafts in biological membranes. Annu. Rev. Cell Dev. Biol., 1998; 14:111-136.

11. Quest A.F., Leyton L., Parraga M. Caveolins, caveolae, and lipid rafts in cellular transport, signaling, and disease. Biochem. Cell Biol., 2004; 82:129-144.

12. Ilangumaran S., Hoessli D.C. Effects of cholesterol depletion by cyclodextrin on the sphingolipid microdomains of the plasma membrane. Biochem. J., 1998; 335:433-440.

13. Barenholz Y. Sphingomyelin and cholesterol: from membrane biophysics and rafts to potential medical applications. Subcell. Biochem., 2004; 37:167-215.

14. Lambert D., O'Neill C.A., Padfield P.J. Depletion of Caco-2 cell cholesterol disrupts barrier function by altering the detergent solubility and distribution of specific tight-junction proteins. Biochem. J., 2005; 387:553-560.

15. Lambert D., O'Neill C.A., Padfield P.J. Methyl- $\beta$ cyclodextrin increases permeability of caco- 2 cell monolayers by displacing specific claudins from cholesterol rich domains associated with tight junctions. Cell. Physiol. Biochem., 2007; 20:495506.

16. Lynch R.D., Francis S.A., McCarthy K.M., Casas E., Thiele C., Schneeberger E.E. Cholesterol depletion alters detergent-specific solubility profiles of selected tight junction proteins and the phosphorylation of occludin. Exp. Cell Res., 2007; 313:2597-2610.

17. Sugibayashi K., Onuki Y., Takayama K. Displacement of tight junction proteins from detergent-resistant membrane domains by treatment with sodium caprate. Eur. J. Pharm. Sci., 2009; 36:246-253.

18. Ohvo-Rekila H., Akerlund B., Slotte J.P. Cyclodextrin-catalyzed extraction of fluorescent sterols from monolayer membranes and small unilamellar vesicles. Chem. Phys. Lipids, 2000; 105:167-178.

19. Piel G., Piette M., Barillaro V., Castagne D., Evrard B., Delattre L. Study of the interaction between cyclodextrins and liposome membranes: effect on the permeability of liposomes. J. Incl. Phenom. Macrocycl. Chem., 2007; 57:309-311.

20. Beseničar M.P., Bavdek A., Kladnik A., Macek P., Anderluh G. Kinetics of cholesterol extraction from lipid membranes by methyl- $\beta$-cyclodextrin A surface plasmon resonance approach. Biochim. Biophys. Acta-Biomembr., 2008; 1778:175-184.

21. Piel G., Piette M., Barillaro V., Castagne D., Evrard B., Delattre L. Study of the relationship between lipid binding properties of cyclodextrins and their effect on the integrity of liposomes. Int. J. Pharm., 2007; 338:35-42.

22. Piel G., Moutard S., Perly B., Henry de Hassonville S.H., Bertholet P., Barillaro V., Piette M., Delattre L., Evrard B. Comparison of two methods currently used to determine the interaction between cyclodextrins and drugs: phase solubility diagrams and NMR spectroscopy. J. Drug Deliv. Sci. Technol., 2004; 14:87-91.

23. Ravichandran R., Divakar S. Inclusion of ring a of cholesterol inside the $\beta$-cyclodextrin cavity: Evidence from oxidation reactions and structural studies. J. Inclusion Phenom. Mol. Recogn., 1998; 30:253-270.

24. Nishijo J., Moriyama S., Shiota S. Interactions of cholesterol with cyclodextrins in aqueous solution. Chem. Pharm. Bull., 2003; 51:1253-1257.

25. Nishijo J., Moriyama S., Shiota S., Kamigauchi M., Sugiura M. Interaction of heptakis (2,3,6-triO-methyl)- $\beta$-cyclodextrin with cholesterol in aqueous solution. Chem. Pharm. Bull., 2004; 52:1405-1410.

26. Piel G., Dive G., Evrard B., Van Hees T., Henry de Hassonville S., Delattre L. Molecular modeling study of $\beta$ - and $\gamma$-cyclodextrin complexes with miconazole. Eur. J. Pharm. Sci., 2001; 13:271279.

27. Henry de Hassonville S., Perly B., Piel G., Van Hees T., Barillaro V., Bertholet P., Delattre L., Evrard B. Inclusion complexes of cyproterone acetate with cyclodextrins in aqueous solution. $\mathrm{J}$. Incl. Phenom. Macrocycl. Chem., 2002; 44:289292.

28. Bertholet P., Gueders M., Dive G., Albert A., Barillaro V., Perly B., Cataldo D., Piel G., Delattre L., Evrard B. The effect of cyclodextrins on the aqueous solubility of a new MMP inhibitor: phase solubility, ${ }^{1} \mathrm{H}-\mathrm{NMR}$ spectroscopy and molecular modeling studies, preparation and stability study of nebulizable solutions. J. Pharm. Pharm. Sci., 2005; 8:147-158.

29. Ziémons E., Dive G., Debrus B., Barillaro V., Frédérich M., Lejeune R., Angenot L., Delattre L., Thunus L., Hubert P. Study of the physicochemical properties in aqueous medium and molecular modeling of tagitinin $\mathrm{C} /$ cyclodextrin complexes. J. Pharm. Biomed. Anal., 2007; 43:910-919.

30. Barillaro V., Dive G., Bertholet P., Evrard B., Delattre L., Ziémons E., Piel G. Theoretical and experimental investigations on miconazole/cyclodextrin/acid complexes: Molecular modeling studies. Int. J. Pharm., 2007; 342:152-160. 
31. Dewar M.J.S., Zoebisch E.G., Healy E.F., Stewart J.J.P. AM1: a new general purpose quantum mechanical molecular model. J. Am. Chem. Soc., 1985; 107:3902-3909.

32. Dive G., Dehareng D., Ghuysen J.M. Energy analysis on small to medium sized H-bonded complexes. Theor. Chim. Acta, 1993; 85:409-421.

33. Jensen F. Introduction to computational chemistry. John Wiley \& Sons, Wiley-VCH, Chichester, UK, 1999.

34. Hariharan P.C., Pople J.A. The influence of polarization functions on molecular orbital hydrogenation energies. Theor. Chim. Acta, 1973, 28:213-222.

35. Becke A.D. Density-functional thermochemistry. III. The role of exact exchange. J. Chem. Phys., 1993; 98:5648-5652.

36. Frisch M.J., Trucks G.W., Schlegel H.B., Scuseria G.E., Robb M.A., Cheeseman J.R., Montgomery J.A. Jr., Vreven T., Kudin K.N., Burant J.C., Millam J.M., Iyengar S.S., Tomasi J., Barone V., Mennucci B., Cossi M., Scalmani G., Rega N., Petersson G.A., Nakatsuji H., Hada M., Ehara M., Toyota K., Fukuda R., Hasegawa J., Ishida M., Nakajima T., Honda Y., Kitao O., Nakai H., Klene M., Li X., Knox J.E., Hratchian H.P., Cross J.B., Adamo C., Jaramillo J., Gomperts R., Stratmann R.E., Yazyev O., Austin A.J., Cammi R., Pomelli C., Ochterski J.W., Ayala P.Y., Morokuma K., Voth G.A., Salvador P., Dannenberg J.J., Zakrzewski V.G., Dapprich S., Daniels A.D., Strain M.C., Farkas O., Malick D.K., Rabuck A.D., Raghavachari K., Foresman J.B., Ortiz J.V., Cui Q., Baboul A.G., Clifford S., Cioslowski J., Stefanov B.B., Liu G., Liashenko A., Piskorz P., Komaromi I., Martin R.L., Fox D.J., Keith T., AlLaham M.A., Peng C.Y., Nanayakkara A., Challacombe M., Gill P.M.W., Johnson B, Chen W, Wong M.W., Gonzalez C., Pople J.A., Gaussian, Inc., Wallingford CT, 2004. Gaussian 03, Revision D.02.
37. Armspach D. Gattuso G., Koniger R., Stoddart J. "Cyclodextrins" in Bioorganic Chemistry: carbohydrates Ch 12, Ed. Hecht Sidney M. Oxford University Press 1999

38. Hazekamp A., Verpoorte R. Structure elucidation of the tetrahydrocannabinol complex with randomly methylated $\beta$-cyclodextrin. Eur. J. Pharm. Sci., 2006; 29:340-347.

39. Bakkour Y. Etude par RMN des complexes d'inclusion avec des cyclodextrines natives et polymérisées. Université des Sciences et Technologies de Lille 1, Lille, France, 2005.

40. Comini S., Mentink L. Refining mixtures containing complexes of cyclodextrins with lipophilic compounds such as fatty acids. Eur Pat. Appl. EP 440539, 1991.

41. Szente L., Szejtli J. Cyclodextrins as food ingredients. Trends Food Sci. Technol., 2004; $15: 137-142$. 